\title{
A educação de qualidade no Direito Constitucional Brasileiro e a reforma do Ensino Médio*
}

\author{
Patrícia de 0 liveira A ssumpção B ertuol \\ Universidade Estadual Paulista (UNESP), A raraquara - SP - Brasil. \\ M estranda pelo PPG Educação Escolar - Á rea de Políticas e G estão \\ E ducacional. A dvogada, professora de D ireito. bertuol.advocacia@gmail.com
}

\footnotetext{
${ }^{*}$ T exto resultado de um diálogo entre as áreas de E ducação e D ireito.
} 


\section{Resumo}

E ste artigo versa sobre o direito subjetivo a uma educação de qualidade e sua trajetória normativa na perspectiva interdisciplinar de Direito e E ducação, especificamente, do $D$ ireito Constitucional à Educação e a recente reforma do $E$ nsino $M$ édio brasileiro. Vincula-se às atividades de Pesquisa de M estrado em Educação E scolar pela U nespFCLAr e aos estudos interdisciplinares do G rupo de Pesquisa em Políticas Públicas E ducacionais no Brasil. Em base metodológica de pesquisa qualitativa em educação, articulada à metodologia hipotético dedutiva e análise jurídica argumentativa-dialética com destaque para pesquisa documental de base legal. Priorizou-se abordar a Constituição B rasileira de 1988 (CF), o E statuto da C riança e do A dolescente (E C A ) e a L ei de Diretrizes de Bases da Educação - Lei 9.394/96 (LDB). Cabe destacar a relevância social dessa temática com ênfase no direito constitucional à uma educação de qualidade. Foi abordada a importância na formação de operadores do direito iterados sobre o tema para a eficaz efetivação desse direito público subjetivo e os indicadores de qualidade para a comunidade.

Palavras-chave: Direito C onstitucional à E ducação. 0 peradores do D ireito. Políticas E ducacionais.

\section{Abstract}

A BST RACT: This article deals with the subjective right to a quality education and its normative trajectory in the interdisciplinary perspective of $L a w$ and $E$ ducation, specifically, of the Constitutional Right to Education and the recent reform of the Brazilian $\mathrm{H}$ igh School. It is linked to the activities of M aster's Research in School $E$ ducation by U nesp-FCL Ar and to the interdisciplinary studies of the Research $G$ roup on Public Educational Policies in Brazil. On methodological basis of qualitative research in education articulated to the hypothetical deductive methodology and argumentative-dialectical juridical analysis with emphasis on documental research with legal basis. It was prioritized to address the Brazilian Constitution of 1988 (CF), the Statute of the $C$ hild and A dolescent (ECA) and the $L$ aw of Basic E ducation $G$ uidelines - Law 9.394 / 96 (LDB). It is important to highlight the social relevance of this issue with emphasis on constitutional law to a quality education. It was approached the importance in the training of legal operators iterated on the subject for the effective realization of this subjective public right and the indicators of quality for the community.

K eywords: C onstitutional R ight to $E$ ducation. $O$ perators of $L$ aw. E ducational Policies. 


\section{Introdução}

A motivação que norteia a elaboração deste significa, sobretudo, a possibilidade de aprofundamento teórico-metodológico para entender porque a educação - um direito social público subjetivo - não se materializa com a qualidade capaz de assegurar a todas as crianças, adolescentes e jovens, 0 ingresso, a permanência e o sucesso na escola. D essa forma, o objetivo do presente trabalho é analisar a aprovação da lei 13.415/17, que versa sobre a reforma do E nsino $\mathrm{M}$ édio, utilizando como orientador seu trâmite legislativo e as ações judiciais propostas sobre o tema. 0 trabalho apresenta uma abordagem qualitativa e se caracteriza como uma pesquisa de análise bibliográfica e documental .

O jurista alemão Georg Jellinek, cuja obra, publicada em 1892, é um marco para a temática, definiu Direito Público Subjetivo como "o poder da vontade humana que, protegido e reconhecido pelo ordenamento jurídico, tem por objeto um bem ou interesse" (JELLINEK, 1910, p.10). Em outras palavras, o direito público subjetivo confere ao indivíduo a possibilidade de transformar a norma geral e abstrata contida num determinado ordenamento jurídico em algo que possua como próprio. A maneira de fazê-lo é acionando as normas jurídicas (direito objetivo) e transformando-as em seu direito (direito subjetivo).

0 Brasil, a partir do advento da Constituição de 1988, filiou-se à ideia de que crianças e adolescentes são sujeitos de direitos, podendo exercitá-los frente à família, à sociedade, e ao E stado (art. 227), o que foi complementado pelo Estatuto da Criança e do Adolescente (ECA) - que instituiu os Sistemas de Garantias, aprofundado pela L D B. São também sujeitos de direito à educação: direito irrenunciável e inalienável.

A ssim, crianças, adolescentes e jovens são sujeitos de direitos e destinatários de políticas públicas, com critério emergencial e prioritário para atendimento. Tendo 0 Estado o dever incontestável de atender às necessidades individuais como saúde, educação, alimentação, habitação, transporte, lazer, entre outros, surge, da omissão estatal, a competência restauradora do direito violado. A Constituição Federal Brasileira de 1988 (CF) e o E statuto da Criança e do A dolescente - L ei 8.069/1990 (E CA) dão suporte jurídico à concretização dessas garantias, indicando os instrumentos judiciais e os agentes propulsores encarregados da manutenção e/ ou resgate do direito.

Dentre as garantias constitucionais, ressalta-se a garantia da qualidade educacional, que é uma garantia utilizada como argumento pelo Poder Executivo para a 
nova reforma do Ensino M édio brasileiro, dentro das diretrizes debatidas pela Base Comum Curricular.

Para analisar essa temática (caso) foi utilizado o método hipotético-dedutivo de Popper (1975) e testada uma solução baseada na argumentação dialético-indutiva (LAKATOS; MARCONI, 2003, p. 58) articulada com a pesquisa qualitativa em E ducação.

A ponta a L ei n. 13.005/2014 em seu art. 13 que

[...] o poder público deverá instituir, em lei específica, contados 2 (dois) anos da publicação desta L ei, o Sistema $\mathrm{N}$ acional de E ducação, responsável pela articulação entre os sistemas de ensino, em regime de colaboração, para efetivação das diretrizes, metas e estratégias do Plano N acional de E ducação.

Desse modo, o M inistério da Educação (MEC) apresentou projeto de lei complementar que institui o Sistema $\mathrm{N}$ acional de $\mathrm{E}$ ducação e fixa normas da cooperação federativa entre a U nião, os estados, o D istrito F ederal e os municípios, entre os estados e os seus municípios e entre os municípios; trata-se do projeto: PL P № 413/2014.

No referido projeto, além das normas referentes à cooperação entre os entes federativos, trata também da garantia dos meios de acesso à educação pública básica e superior regida pela L ei de D iretrizes de B ases da $E$ ducação $N$ acional (LDB).

Reforça a Lei n. 13.005/2014 em seu art. 3o, os princípios constitucionais referentes à E ducação do art. 206 da C onstituição.

Salienta que caberá à União a coordenação da política nacional de educação, articulando os diferentes níveis e sistemas e exercendo função normativa, bem como que os sistemas de ensino terão liberdade de organização nos termos da referida lei (projeto) e da LDB.

O objetivo do Sistema Nacional de Educação é garantir a universalização da educação e seu padrão de qualidade no território nacional, observando diversos preceitos traçados nos incisos do art. 50 do referido projeto de lei complementar.

N este contexto de um novo sistema nacional educacional, com ampla discussão nacional, veio à baila a reforma do $\mathrm{E}$ nsino $\mathrm{M}$ édio brasileiro.

Sendo a educação um direito assegurado pela C onstituição Federal de 1988 (art. 205 a 214), pelo E statuto da C riança e do A dolescente ( $L$ ei $n .0$ 8.069/90) e pela L ei de 
D iretrizes e Bases da E ducação N acional (L ei $n .0$ 9.394/96), além de outros numerosos instrumentos legais e normativos dos sistemas educacionais, em nossos estudos, vale ressaltar que a educação de qualidade é assegurada pelo art. 206, VII da Constituição Federal, sendo instigante, assim, o fato de que milhões de crianças e jovens não têm o atendimento, nas escolas básicas, em níveis de qualidade aceitáveis.

R essalta-se que a educação entre os autores do D ireito e em conformidade com a Constituição não é um bem, mas sim um direito público subjetivo, que de tão valioso e importante foi ressaltado por Morais como a 'mercadoria' mais relevante socialmente (nota- se que o termo consta entre aspas).

\section{Fundamentação Teórica}

0 direito tutela interesses individuais e sociais, protegendo-os com a força da organização social. N o Estado de Direito, as soluções dos conflitos obedecem aos primados da lei, em todos os setores da vida nacional, e na área educacional não poderia ser diferente (M AZZIL LI, 2000).

O exercício da cidadania é conquista do Estado democrático de direito, que se consolida no efetivo atendimento dos direitos fundamentais, anunciados na ordem jurídica vigente (SILVA, 1997). A cidadania reclama atendimento aos interesses protegidos pela lei, como direitos fundamentais, essenciais para o desenvolvimento da pessoa humana e a manutenção da própria dignidade.

O E stado, concebido como nação politicamente organizada, para o atendimento de seus objetivos primordiais, é responsável pela definição de políticas sociais básicas, implementando ações e serviços coletivos que resultem em benefícios concretos para a população (BO N A VID ES, 2003). A C arta M aior estabelece que são direitos sociais: a educação, a saúde, o trabalho, o lazer, a segurança, a previdência social, a proteção à maternidade e à infância, a assistência aos desamparados (C F , art. 6ㅇ)

Conceitualmente, podemos definir o termo problema em políticas públicas como sendo a discrepância entre a situação percebida e a desejada (SE C C H I, 2013).

N esse aspecto, é discrepante a situação percebida em relação à educação no ensino médio e a desejada, em especial quanto à qualidade. A ssim, observamos uma inadequação na forma como foi aprovada a medida provisória (M P) n 746/16 de reforma do $\mathrm{E}$ nsino $\mathrm{M}$ édio. $\mathrm{N}$ ecessária se faz a promoção da participação da sociedade 
civil e também de representantes de instituições da área da educação, bem como de especialistas e pesquisadores, na definição e reflexão acerca do problema, em especial a qualidade educacional pleiteada.

E sse aspecto participativo presente nas políticas públicas foi negado à sociedade no momento em que o governo apresenta uma M $P$, medida esta sem amplo debate, surgindo como medida impositiva do poder executivo, com suposta urgência e relevância para alteração da $L D B$, feita de maneira autoritária e hierárquica sem prévia consulta à sociedade.

A pós diversas manifestações contrárias a esse processo legislativo, realizadas pela sociedade e também por profissionais da área jurídica, o governo mantém a postura autoritária, mas dá continuidade ao processo de aprovação do texto; no entanto, promove 0 andamento através do projeto de lei de conversão $\mathrm{n}$. 34 e posteriormente a aprovação da L ei n. 13.415/2017.

Esse caráter de urgência inerente às medidas provisórias não permite que 0 problema seja discutido, refletido e analisado sob diferentes aspectos e com a participação de diversos interlocutores que possam contribuir para solucionar 0 problema elencado, em especial quanto ao aspecto da qualidade da nova proposta de ensino médio que se propõe.

A Constituição garante também que 0 acesso à educação fundamental é obrigatório e gratuito e constitui direito público subjetivo (CF, art. 208, §1으), o que possibilita sua exigência em juízo ou fora dele, por estar inscrito no texto constitucional, como garantia de proteção prioritária. A lei, portanto, permite que os interessados ingressem em juízo, pugnando ao Poder Judiciário providência asseguradora de seus direitos relacionadas à universalização do atendimento escolar, à melhoria da qualidade do ensino, à formação para o trabalho, e à promoção humanística, científica e tecnológica do País (CF, art. 214).

Q uando uma violação dos direitos é identificada, esta deve ser situada dentro de uma categoria adequada, para depois escolher o remédio constitucional apropriado para sua defesa. A defesa dos interesses difusos, coletivos e individuais homogêneos pode ser efetivada tanto na área administrativa quanto na judicial. $\mathrm{N}$ a via administrativa, temos a atuação dos $C$ onselhos T utelares; nos procedimentos administrativos de competência do M inistério Público, conferidos pela C onstituição Federal (art. 129, VI e VIII), temos 0 inquérito civil, instrumento preparatório da ação civil pública. 
A CF estabeleceu, também, balizas para o estabelecimento da política de educação a ser implantada no Brasil, priorizando ações que considera essenciais para o desenvolvimento das pessoas e do País. A educação, como dever do Estado, importa desenvolvimento de ações governamentais que conduzam ao atendimento em creche e pré-escola, no ensino fundamental, no ensino médio e no superior, além do atendimento educacional especializado às pessoas portadoras de deficiência. No artigo 208 da C F , o Estado (aqui e na L ei M aior utilizado como designativo do poder público) deve promover a progressiva universalização do ensino médio gratuito, oferecer ensino noturno regular e atender ao educando, no ensino fundamental (gratuito nas escolas públicas).

Para assegurar a qualidade desejável dos processos educacionais a CF prevê, também, o funcionamento de programas suplementares de material didático-escolar, transporte, alimentação e assistência à saúde (art. 208, VII). 0 que, somado às disposições da LDB de que o "ensino fundamental será ministrado progressivamente em tempo integral, a critério dos sistemas de ensino" ( $\operatorname{art.34} \$ 2^{\circ}$ ) e que "será objetivo permanente das autoridades responsáveis alcançar relação adequada entre o número de alunos e o professor, a carga horária e as condições materiais do estabelecimento" (art. 24, VII), poderá possibilitar ações de exigibilidade de direitos junto aos governos.

I sto porque, a CF (art. 211), seguida pela LD B (art. 9o), dispõe que a U nião, os estados, o D istrito F ederal e os municípios organizarão os respectivos sistemas de ensino em regime de colaboração. $Q$ uanto aos recursos relacionados à manutenção dos sistemas educacionais estabeleceu a CF a obrigatoriedade do uso de parte da receita resultante de impostos: a U nião, no limite mínimo de dezoito por cento e E stados, D istrito F ederal, e M unicípios, percentual nunca inferior a vinte e cinco por cento (art. 209).

Reiterando a ideia apresentada no texto introdutório, no Brasil, a partir do advento da CF de 1988, crianças e adolescentes são sujeitos de direitos (são cidadãos e não futuros cidadãos) podendo exercitá-los frente à família, à sociedade, e ao Estado (art. 227), o que foi complementado pelo E statuto da C riança e do A dolescente (ECA ). São sujeitos de direito à educação: direito irrenunciável e inalienável.

A ssim, são D ireitos F undamentais do E ducando: I gualdade de condições para acesso e permanêndia na escola (CF, art. 206, I) e (ECA, art. 53, I); D ireito ao respeito (CF, art. 227), (ECA, art. 17) e (LDB, art.3o, IV); Direito de contestar critérios avaliativos (ECA art. 53, III); D ireito de organização e partia pação em entidades estudantis (E C A , art. 
53, IV) e (CF, art. 50, XVII); Direito à escola próxima da residência - uma decorrência natural da "doutrina da proteção integral" consagrada pelo ECA.

$E$, no conjunto da sociedade - educandos, pais e a população em geral - esperase que o direito à educação baseada nos princípios de "garantia de padrão de qualidade" (CF, art.206, VII) seja implementada, com vistas a novos rumos da qualificação e conscientização de direitos.

U ma conscientização que se reverte em processos de reivindicação, uma vez que somente aqueles que conhecem, que têm informação, saber, instrução, criam e dominam meios capazes de levar transformações à sua própria vida e à história. Se a ignorância é a principal arma dos exploradores, a educação de qualidade é o instrumento para a transposição da marginalidade para a cidadania, única medida do desenvolvimento de um povo.

E $m$ relação à educação brasileira de nível médio, a determinação da situação real se apresenta a partir dos resultados das avaliações de conhecimento para esta etapa do ensino básico, o Exame $N$ acional do Ensino $M$ édio ( $E N E M$ ), além de outras informações de caráter administrativo como taxa de evasão, reprovação e abandono.

Os dados apresentados pelas pesquisas do Censo 2016 indicam que o Ensino M édio brasileiro apresenta diferentes dificuldades desde a matrícula e manutenção do aluno nesta etapa do ensino até a qualidade da aprendizagem dos conteúdos estudados, ou seja, pode-se considerar a qualidade do E nsino M édio brasileiro como um problema sob a perspectiva da política pública. A pós a definição de um determinado tema como um problema público, iniciam-se as disputas para inseri-lo na agenda formal dos governos representantes do E stado no presente momento.

$N$ esse contexto, identificada a necessidade de busca de uma solução para 0 problema do Ensino M édio B rasileiro, foi realizada sua reforma, que é um conjunto de novas diretrizes para o ensino médio implementadas via $M$ edida Provisória apresentada pelo governo federal em 22 de setembro de 2016. Por se tratar de uma medida provisória, o texto teve força de lei desde a publicação no "Diário Oficial". Para não perder a validade, precisava ser aprovado em até 120 dias (4 meses) pelo Congresso $N$ acional.

A M P foi elaborada pelo M inistério da Educação e defendida pelo ministro $M$ endonça Filho, que assumiu a pasta após a posse de Michel Temer, em 1o de setembro de 2016. 
A ntes da M P, estava em tramitação na Câmara o Projeto de L ei no 6840/2013, do deputado Reginaldo Lopes (PT - M G ). Entidades como o M ovimento $\mathrm{N}$ acional pelo E nsino M édio defendiam a continuidade da tramitação e das discussões sobre o PL. Governo e congressistas dizem que o conteúdo da MP considera discussões da C omissão E special que resultou no PL.

Por um futuro melhor para a educação é preciso pensar a escola como um lugar privilegiado para o encontro da criança e do jovem com o saber sistematizado, na busca da qualificação intelectual e do desenvolvimento emocional e afetivo. Considerando a complexidade de tais conhecimentos, habilidades, atitudes e valores éticos (que não podem ser improvisados), mas construídos em longo e sistematizado processo - a escola deve ser pensada com o cuidado devido.

U ma educação escolar de qualidade que, devidamente cuidada pelos poderes públicos das três esferas, deve ser exigida pelo conjunto da sociedade. U ma educação que, no mínimo, atenda a indicadores da área educacional que permitem ações seguras sobre o interior da escola e da sala de aula. Há, inclusive, uma vasta literatura internacional, com base de consenso bastante alargada, que possibilita caracterizar formas criativas de organização, acompanhamento e avaliação de uma escola de qualidade (PORTE LA, 2000, p. 367).

\section{INDICADORESDE QUALIDADE APONTADOS}

$N$ ão se pode falar em qualidade de educação escolar sem antes questionar de que qualidade se está falando. A partir dos anos 60 , surge uma vasta literatura com estudos realizados tanto pela Sociologia da E ducação inglesa, quanto pesquisas da A ntropologia norte-americana. N o B rasil, os estudos se desenvolvem a partir do final da década de 70 : tem-se um vasto acervo do funcionamento do cotidiano escolar baseado em estudos de caso ou pesquisas de caráter regional, com bases de consensos bastante alargadas (PO RT E L A , 2000), estabelecendo os seguintes indicadores da qualidade educacional: 
10 indicador - A G estão da E scola - é um dos indicadores de qualidade de uma instituição, e tende a reproduzir as formas de gestão do sistema educacional, no seu todo ou parte. Por imposição legal, na escola pública, a gestão deve ser democrática, pressupondo:

a) a autonomia e a participação de todos os segmentos envolvidos,

b) atitude de respeito à diversidade e ao pluralismo,

c) ênfase no coletivo.

Como vantagens, a literatura aponta que a gestão democrática se caracteriza pelo: a) comprometimento de todos os segmentos com o trabalho da escola; b) redução das relações manipulativas; c) instalação de um clima favorável ao trabalho e à aprendizagem; d) redução da dependência vertical e ampliação da integração horizontal.

20 indicador - A U tilização do T empo, oficialmente: ano letivo com $800 \mathrm{~h}$ em 200 dias, mas temos uma realidade não muito animadora. $\mathrm{Na}$ prática, pesquisas mostram que as escolas funcionam em período menor. E m muitas escolas não há aulas em dias de provas, de planejamento e/ ou capacitação de professores.

3o Indicador - A O rganização do E spaço, item básico no cotidiano da escola. A delimitação e organização dos espaços mostram a valoração implícita das atividades. A aparência da escola, a disposição do mobiliário e dos equipamentos, a limpeza, a distribuição de cartazes, a arrumação das salas, a existência de espaços para a convivência, etc., marcam a escola como um lugar agradável, ou um lugar onde não se tem vontade de ficar. 0 espaço reflete a concepção do trabalho pedagógico ou é determinado por ele, favorecendo ações participativas, trabalhos coletivos ou individualizados, obediência, tranquilidade, agitação. M esmo não sendo determinante, 0 espaço favorece, ou não, o sucesso ou o fracasso do trabal ho.

A realidade mostra diversificados retratos de espaços físicos, desde escolas tecnicamente muito bem organizadas/equipadas, até ambientes que degradam 0 ser humano.

4 Indicador - A C omposição e D inâmica C urricular, prescritas pela CF e L D B indicam currículo da educação básica: uma base nacional comum obrigatória, dimensão obrigatória definida pela U nião, a ser complementada, em cada sistema e na escola, por 
uma parte diversificada, exigida pelas características regionais e locais da sociedade, da cultura, da economia e da clientela.

A concepção restrita de currículo, muitas vezes, confundido com grade curricular, está substituída por uma concepção mais ampla que considera o contexto escolar e os fatores que nele incidem. A interdisciplinaridade e a transdisciplinaridade devem permear o trabalho pedagógico, com uma coordenação do conhecimento em um sistema lógico que permite o livre trânsito de um campo de saber para outro. A ssim, temas transversais, privilegiando aspectos da vida cidadã (saúde, sexualidade, vida familiar, meio ambiente, trabalho, trânsito, linguagens...), junto com as áreas do conhecimento comporão a base do currículo formal, real da instituição.

B oas orientações dos sistemas favorecem o trabalho dos professores. 0 rientações autoritárias, inadequadas, sem clareza e sem objetividade levam à insegurança.

5o Indicador - A 0 rientação D idática fundamentada no pluralismo de ideias e de concepções pedagógicas está prevista na legislação educacional. M as, o modelo de aula com o professor à frente, expondo seu saber, e os alunos enfileirados, tem sido 0 mais disseminado nas escolas. 0 foco é no professor e no ensino, quando deveria ser no aluno e na aprendizagem. 0 surpreendente é que esse tradicionalismo vem resistindo a uma produção considerável de teorias, originadas e complementadas por um número incalculável de pesquisas. Esse conhecimento inspira diferentes propostas pedagógicas em sala de aula e vem comprovando a ineficiência do modelo tradicional.

60 Indicador - A Valorização dos Profissionais, condição imprescindível à qualidade da escola. Os sistemas devem assegurar a existência de estatutos e planos de carreira, condições de trabalho incluindo horas-atividade, mínimos de habilitação para cada nível de atuação.

No entanto, há problemas generalizados de toda ordem na formação e na atuação dos professores. A s licenciaturas não têm contribuído para qualquer mudança. 0 discurso vale pelo discurso e os professores das licenciaturas, no ensino superior, não conseguem alterar nem a própria prática. A lém disso, não dispõem de material bibliográfico, nem desenvolvem o hábito e o prazer da leitura, não têm oportunidades para trocas de experiências, não têm recursos (nem tempo) para educação continuada e mostram uma situação de penúria que se reproduz na escola básica. 
70 Indicador - As Formas de A valiação retratam, claramente, o estilo e a qualidade da escola. Seria animador encontrarmos sistemas de avaliação que privilegiassem: avaliação contínua e cumulativa; valoração da aprendizagem com ênfase nos resultados do período letivo; com possibilidade de aceleração e aproveitamento de estudos conforme a situação de cada educando; e estudos de recuperação para valer.

L amentavelmente, a realidade mostra que ela tem sido problemática. A o invés de ter a função de obter informações sobre os avanços e as dificuldades dos alunos, e ser um processo permanente de suporte ao ensino, de orientação ao planejamento do professor na busca do êxito, muitas vezes, é um processo cercado de confusão e insegurança, usado como um instrumento de poder e autoritarismo; discriminação e exclusão; de arbitrariedades contra, geralmente, os socialmente mais fragilizados.

80 Indicador - A Participação de T odos para o sucesso da escola, pais, alunos, autoridades e comunidade em geral, como instrumento da gestão democrática é outro indicativo da qualidade da escola. Está assegurada pela LD B (art 14) e pelo ECA (53). No entanto, no Brasil, a militância familiar e comunitária é, ainda, incipiente. G eralmente não é valorizada como parceira competente, em especial quando faz parte de extratos sociais não escolarizados.

\footnotetext{
A educação que é uma política pública de cobertura universal e que está vinculada ao próprio direito básico da pessoa ao desenvolvimento, será tanto mais respeitada quanto maior for o empenho da sociedade na demanda concreta de operacionalização do direito positivado e quanto maior for a superação dos paradigmas tradicionais que permeiam e empobrecem a leitura da lei (COST A e LIM A, 200, p. 310).
}

99 Indicador - 0 Reconhecimento Público de que a escola é competente e, junto com a comunidade e com seus alunos, é capaz para desempenhar suas funções, sinaliza sobre o que ela é. $Q$ uando os pais fazem esforços para matricular seus filhos em uma escola por razões que ultrapassam a questão de proximidade física; quando a organização dos espaços físicos/prédios chamam positivamente a atenção; quando se generaliza a ideia de que aquela escola preocupa-se com o destino de suas crianças e adolescentes; quando professores e demais funcionários sentem-se orgulhosos por 
pertencerem a ela; quando, enfim, é reconhecida publicamente como uma boa escola: há fortes indícios de que ela realmente o seja!

A pesar desses indicadores de qualidade apresentados, que demonstram uma gestão democrática, participativa e o reconhecimento público de qualidade, o Poder Executivo, com a reforma, flexibiliza o conteúdo que será ensinado aos alunos, muda a distribuição do conteúdo das 13 disciplinas tradicionais ao longo dos três anos do ciclo, dá novo peso ao ensino técnico e incentiva a ampliação de escolas de tempo integral, claramente buscando um impulsionamento econômico do país e não melhoria de qualidade educacional.

O currículo do ensino médio será definido pela Base $\mathrm{Nacional}$ Comum C urricular (BN CC). M as a nova lei já determina como a carga horária do ensino médio será dividida. Tudo o que será lecionado vai estar dentro de uma das seguintes áreas, que são chamadas de "itinerários formativos": 1) linguagens e suas tecnologias; 2) matemática e suas tecnologias; 3) ciências da natureza e suas tecnologias; 4) ciências humanas e sociais aplicadas; e 5) formação técnica e profissional.

A s escolas, pela reforma, não são obrigadas a oferecer aos alunos todas as cinco áreas, mas deverão oferecer ao menos um dos itinerários formativos.

0 texto determina que $60 \%$ da carga horária seja ocupada obrigatoriamente por conteúdos comuns da BNCC, enquanto os demais $40 \%$ serão optativos, conforme a oferta da escola e interesse do aluno, mas também seguindo o que for determinado pela B ase N acional. No conteúdo optativo, o aluno poderá, caso haja a oferta, se concentrar em uma das cinco áreas mencionadas acima.

$O$ utro objetivo da reforma é incentivar 0 aumento da carga horária para cumprir a meta 6 do Plano N acional de E ducação (PNE), que prevê que, até 2024, 50\% das escolas e $25 \%$ das matrículas na educação básica (incluindo os ensinos infantil, fundamental e médio) estejam no ensino de tempo integral.

No ensino médio, a carga deve agora ser ampliada progressivamente até atingir 1,4 mil horas anuais. A tualmente, o total é de 800 horas por ano, de acordo com 0 MEC.

E m relação ao conteúdo da reforma, este foi alvo de muita polêmica, tendo inclusive gerado protestos e ocupações de escolas por estudantes em todo o Brasil, ocasionando o adiamento o Exame $\mathrm{N}$ acional do Ensino M édio (Enem) em 2017. 
D entre as polêmicas estão a retirada de disciplinas obrigatórias como artes, educação física, sociologia e filosofia, e a inclusão da língua inglesa como obrigatória.

$M$ as, em especial, ressalta-se a permissão para que professores sem diploma específico possam ministrar aulas, pois o texto prevê profissionais com "notório saber", bem como profissionais graduados sem licenciatura, que poderão fazer uma complementação pedagógica para dar aulas.

\section{Trâmite legislativo da lei n. 13.515/2017}

Passando da polêmica em relação ao conteúdo da reforma, outra que se faz presente é a forma que foi implementada a mesma. Como destacado, a lei $n$. 13.515/2017, conhecida como a reforma do ensino médio, não se trata de um consenso na sociedade, não refletindo os anseios da mesma, já que legalmente representa a conversão de uma M edida Provisória, questionada judicialmente por uma A ção D ireta de Inconstitucionalidade, em um projeto de lei, convertido às pressas.

0 então Procurador-geral da República, Rodrigo Janot, enviou parecer ao Supremo T ribunal Federal (STF) no qual afirma que a medida provisória que estabelece uma reforma no ensino médio é inconstitucional.

Conforme 0 acordo com o M inistério da Educação (MEC), a reforma do Ensino $M$ édio foi editada por medida provisória devido à urgência que esse tema se constitui na agenda nacional e considerando que a pouca qualidade do ensino no Brasil é causa do problema econômico que o país vivenciava.

$\mathrm{Na}$ C âmara, a proposta recebeu 567 emendas de deputados e senadores com 0 objetivo de alterar o conteúdo da proposta.

T al medida fere a Constituição Federal e o PNE, especialmente quando impede a participação e controle social sob essa demanda. Para finalizar esse conjunto de ações ilegais e autoritárias, é preciso ficar claro que a edição de uma medida provisória para tratar dessa temática também se configura como inadequada.

No artigo 62 da C onstituição F ederal de 1988 (C F/88) são indicados os casos que são possíveis à edição de MP: "Art. 62. Em caso de relevância e urgência, o Presidente da República poderá adotar medidas provisórias, com força de lei, devendo submetê-las de imediato ao Congresso Nacional." (EC no 32/2001). 
Com a simples observância do artigo 62 da Carta M agna, nota-se que 0 requisito da urgência não se faz presente em relação ao tema, razão da propositura de duas Ações Diretas de Inconstitucionalidade, (ADIs 5599 e 5604), ajuizadas, respectivamente, pelo Partido Socialismo e Liberdade (Psol) e pela Confederação $\mathrm{N}$ acional dos T rabalhadores em E ducação (CNTE) contra a M edida Provisória (M P) 746/2016, que instituiu a reforma do ensino médio.

0 então Procurador-geral da República (PGR), Rodrigo Janot, posicionou-se contra a M edida Provisória do Ensino M édio (M P 746/2016). E m parecer enviado ao Supremo T ribunal Federal (ST F), Janot defende que a M P não apresenta os requisitos de relevância e urgência para edição de medidas provisórias, além de ferir diversos princípios constitucionais. "O desfazimento dos efeitos da concretização da reforma do ensino médio desenhada pela M P 746/2016 conduziria à grave situação de insegurança jurídica e a severos prejuízos pedagógicos e pessoais para toda a comunidade", diz Janot ${ }^{1}$.

A manifestação do PGR faz parte da análise da Ação Direta de Inconstitucionalidade (A DI) 5.599, proposta pelo PSO L. Segundo o partido, a norma viola os pressupostos exigidos pela $\mathrm{C}$ onstituição para edição de medidas provisórias. 0 partido sustenta que seria cristalina a ausência do requisito constitucional da urgência, além de desrespeitar o acesso amplo à educação e dificultar a redução de desigualdades, ao promover verdadeiro retrocesso social.

Segundo Janot, medida provisória, por seu próprio rito abreviado, não é instrumento adequado para reformas estruturais em políticas públicas, "menos ainda em esfera crucial para o desenvolvimento do país, como é a educação". "Demonstração concreta de faltar urgência para edição precipitada da norma está no fato de que, se aprovada pelo C ongresso $\mathrm{N}$ acional ainda em 2016, a reforma só será adotada nas escolas em 2018", argumenta.

Janot destacou no parecer que a discussão da Base $\mathrm{N}$ acional Comum C urricular (BNCC) é complexa e vem sendo feita de maneira participativa há anos e "não se pode admitir que projeto dessa magnitude e relevância seja precipitado". De acordo com procurador, o próprio M inistério da $E$ ducação $(M E C)$ demonstra em seu site a complexidade do projeto e a necessidade de participação democrática e amadurecimento.

\footnotetext{
${ }^{1}$ D isponível em: http://agenciabrasil.ebc.com.br/politica/noticia/2016-12/pgr-defende-inconstitucionalidade-da-mpdo-ensino-medio. A cesso em 20/05/2018.
} 
$N$ ão parece aceitável nem compatível com os princípios constitucionais da finalidade, da eficiência e até da razoabilidade que tal matéria, de forma abrupta, passe a ser objeto de normas contidas em medida provisória, que atropelam, do dia para a noite, esse esforço técnico e gerencial do próprio MEC, em diálogo com numerosos especialistas e com a comunidade, ao longo de anos", disse o PGR.

Para Janot, mudanças a serem implantadas em sistema que envolve 28 redes públicas de ensino (U nião, estados e $D$ istrito F ederal) e ampla rede privada precisam de amadurecimento, estabilidade e segurança jurídica, que o instrumento da medida provisória não pode conferir por estar sujeito a alterações em curto espaço de tempo pelo Congresso $\mathrm{N}$ acional.

O M inistério da Educação criticou o parecer da PGR. Por meio de nota, afirmou que, apesar de respeitar o posicionamento de Janot, mantém o entendimento de que a MP obedece ao requisito constitucional da urgência e relevância. "É urgente apresentar à sociedade uma proposta para enfrentar o flagelo do ensino médio. É importante lembrar que, há 20 anos, o país discute a reforma do ensino médio sem avançar para torná-la realidade. Destaca ainda, que a MP teve admitida a sua constitucionalidade pelo Congresso Nacional", disse².

E $\mathrm{m}$ que pese a nota do MEC, fato é que após as referidas $A$ ções $D$ iretas de Inconstitucionalidade e o parecer do M inistério Público (PGR), a M edida Provisória virou um projeto de conversão que se transformou em lei, passando por nove audiências públicas antes de sua aprovação.

\section{Considerações Finais}

A ssim, resta demonstrado que $0 \mathrm{D}$ ireito $\mathrm{C}$ onstitucional Brasileiro se preocupou com a educação, seu acesso e em especial sua qualidade. Do mesmo modo o fez a legislação infraconstitucional que, além de garantir a qualidade, deu instrumentos para que os operadores do direito, em especial advogados e promotores, ingressem com ações ordinárias, civis públicas, mandados de segurança, entre outras, para resguardar essa qualidade.

\footnotetext{
2 Disponível em: http://agenciabrasil.ebc.com.br/educacao/noticia/2016-12/mec-contesta-parecer-de janot-sobre medida-provisoria-do-ensino-medio . A cesso em 20/05/2018.
} 
Vale ressaltar que os indicadores de qualidade da educação não podem, obviamente, ser construídos se ficarem, só e exclusivamente, sob a responsabilidade daqueles que militam na escola. Somente um diálogo permanente, com as mais diferentes e complementares instâncias sociais, permitirá o aperfeiçoamento das estruturas e o funcionamento da educação escolar. Um diálogo que indicará, ou não, a necessidade da utilização dos instrumentos de exigibilidade do direito à escola de qualidade que nossas crianças merecem.

0 importante a destacar, quanto à orientação didática da escola básica é que, independente da teoria que Ihe dá suporte, deve-se reconhecer as experiências de vida dos participantes do ambiente escolar, ao optar-se por uma determinada concepção pedagógica. 0 aluno, em vez de figurante, tem que ser o protagonista do processo de ensino-aprendizagem, e o professor, seu colaborador. $M$ as, a adoção dessa perspectiva supõe aprofundamento teórico, apoio contínuo, condições favoráveis à aprendizagem, e, sobretudo, mudança de concepção quanto ao sentido do trabalho pedagógico. A aula deve ser uma situação de encontro do professor e seus alunos, na construção de novos saberes.

Por fim, na perspectiva da construção de uma educação escolar de qualidade, 0 papel dos profissionais do direito ficou claro na situação da reforma do Ensino M édio, com as proposituras das A ções D iretas de Inconstitucionalidade por advogados, parecer do M inistério Público, alteração da realidade com a conversão da lei e decisão final do Supremo T ribunal F ederal.

D ecisão esta que foi dada pelo relator, ministro Edson Fachin, do Supremo Tribunal Federal, julgando extintas as duas Ações Diretas de Inconstitucionalidade (ADIs 5599 e 5604), ajuizadas, respectivamente, pelo Partido Socialismo e L iberdade (Psol) e pela C onfederação N acional dos T rabalhadores em E ducação (CN T E ) contra a M edida Provisória (M P) 746/2016, que instituiu a reforma do ensino médio.

D e acordo com o relator, é pacífico o entendimento no ST F de que a apreciação de M P pelo Congresso Nacional e sua posterior conversão em lei não constituem imediato obstáculo ao prosseguimento de ação que questione a constitucionalidade de seu teor. "Entretanto, ocorrendo alterações significativas de forma e matéria entre a medida provisória e seu projeto de lei de conversão, permite-se extinguir a ação direta de inconstitucionalidade por perda superveniente de objeto", disse. 
O ministro E dson Fachin apontou que a M P 746/2016 resultou no Projeto de Lei de Conversão 34/2016 e, posteriormente, na Lei 13.415/2017. "Ocorre que, entre as 568 emendas apresentadas ao texto original no âmbito do Congresso $\mathrm{N}$ acional, parte das aprovadas resultou em alterações substanciais do texto", sustentou ${ }^{3}$.

0 relator citou mudanças importantes em relação à implementação de carga horária mínima anual, à previsão do ensino da arte e de educação física como componente obrigatório da educação básica em sua integralidade, ao prazo de implementação e à destinação dos recursos para financiamento da Política de Implementação de Escolas de Ensino M édio em Tempo Integral. D essa forma, 0 ministro Fachin afirmou que houve perda de objeto das duas AD Is, pois o texto original da M P foi significativamente alterado.

$N$ as ações, o Psol e a CNTE alegavam que a M P violava os seguintes artigos da C onstituição F ederal: 62, caput (ausência do requisito da urgência exigido para a edição de medidas provisórias) e 205 e 206 (promoção e princípios da educação).

Dessa forma, mesmo tendo sido extinta sem análise do mérito, as ações propostas fizeram com que o trâmite legislativo da reforma fosse diverso do inicialmente proposto pelo Executivo.

A ssim, sanado estava o vício formal, ou seja, aquele que afeta a forma de implementação da lei, mas o vício material, em especial relacionado à promoção e princípios da educação, tais como a qualidade, ainda está posto, pois a realidade das políticas públicas educacionais do E nsino M édio e sua real implementação irão mostrar se os objetivos, metas e princípios legais e constitucionais relacionados à qualidade serão al cançados a contento.

\section{Referências}

BO N A VIDES, P. Curso de D ireito Constitucional.13 ed. São Paulo: M alheiros, 2003

BRA SI L . Constitui ção F ederal. 6 ed. São Paulo: RT , 05.01.2004.

Disponível em: http://www.stf.jus.br/portal/cms/verN oticiaD etalhe.asp?idC onteudo=342593. A cesso em 20.05.2018. 
BRA SI L . A gência. M E C contesta parecer deJ anot sobre M edida Provisória do E nsino M édio. D isponível em: «http://agenciabrasil.ebc.com.br/educacao/noticia/201612/mec-contesta-parecer-de-janot-sobre-medida-provisoria-do-ensino-medio $>$. A cesso em: 20 maio 2018.

BRA SIL. A gência. PGR defende inconstitucionalidade da M P do E nsino M édio.

D isponível em: $\measuredangle$ http://agenciabrasil.ebc.com.br/politica/noticia/2016-12/pgr-defendeinconstitucionalidade-da-mp-do-ensino-medio >. A cesso em: 20 maio 2018.

COST A, A . C . G .; LIM A , I. S. O . E statuto e LD B: direito à educação. In: KONZE N, A. Pela J ustiça na E ducação. B rasília: M E C, FUN DESC O L A , 2000, p. 310.

JE LLINEK, G. Sistema dei diritti pubblid subbietivi. M ilano, 1910.

PORTELA, A . L . et al. O Direito de A prender Direito: garantindo a qualidade da educação escolar. In: KO N ZE N, A . P ela Justiça na E ducação. B rasília: M E C, FUN DESC O LA , 2000, p. 349-396.

SE C C H I, L. Políticas públicas: I mprenta: São Paulo: C engage L earning, 2013.

SIL VA , J. A fonso da. Curso de D ireito C onstitucional Positivo. 13 ed. São Paulo: M alheiros, 1997.

ST F. Supremo T ribunal Federal. N otícias ST F . D isponível em: $\varangle$ ttp://www.stf.jus.br/portal/cms/verN oticiaD etalhe.asp?idC onteudo $=342593>$. A cesso em: 20 maio 2018. 